\title{
The Effect of Group Random Quality Control on the First Aid Ability of Ward Doctors and Nurses with Respect to the Resuscitation of Patients with In-Hospital Cardiac Arrest
}

\author{
Jianhong $\mathrm{Ji}^{1}{ }^{1, *}$ \\ Li Wang ${ }^{2, *}$ \\ Haiyang Guan ${ }^{2}$ \\ Yaqiong Jiang' \\ Sanlian Zhou ${ }^{2}$ \\ Junhua Sheng ${ }^{3}$ \\ Lihua Wang ${ }^{4}$
}

'Intensive Care Unit, The Second Affiliated Hospital of Nantong University, Nantong, People's Republic of China;

${ }^{2}$ Department of Emergency, The Second Affiliated Hospital of Nantong University, Nantong, People's Republic of China; ${ }^{3}$ Department of Medical, The Second Affiliated Hospital of Nantong University, Nantong, People's Republic of China; ${ }^{4}$ Department of Nursing, The Second Affiliated Hospital of Nantong University, Nantong, People's Republic of China

*These authors contributed equally to this work

\begin{abstract}
Objective: This study was designed to verify the effect of group random quality control on the first aid ability of ward doctors and nurses with regard to the resuscitation of patients with in-hospital cardiac arrest (IHCA).

Methods: The first aid quality control team of our hospital was established in December 2018, when the number, qualifications, organizational structure, quality control methods, and responsibilities of the team and team members were determined. The baseline data and assessment results of examinees, the rates of return of spontaneous circulation (ROSC), and the discharge survival rate of IHCA patients in 2019 and 2020 were compared. Results: There were no significant differences in the baseline data of examinees at each stage $(p>0.05)$. As time went on, the results of the four practical examinations were significantly improved (pairwise comparison, $\mathrm{p}<0.05$ ). The number of problems in examinations was significantly higher for physicians than for nurses. After guidance in department relearning, the incidence of related problems was significantly reduced, but the mastery of the frequency and depth of extracorporeal cardiac compression were not always up to standard. The proportion of critically ill patients and the incidence of IHCA in the hospital in 2020 was higher than in $2019(\mathrm{p}<0.05)$, and the ROSC rate was also significantly higher than it was in $2019(\mathrm{p}<0.05)$, but the difference in the survival rate at discharge was not statistically significant $(\mathrm{p}>0.05)$.

Conclusion: Group random quality control meets the needs of IHCA emergencies, and it can improve the first aid skills and organizational coordination of doctors and nurses on the ward through continuous discovery and problem solving so that the ultimate goal of improving the success rate of resuscitation can be achieved.
\end{abstract}

Keywords: in-hospital cardiac arrest, cardiopulmonary resuscitation, quality control, patient outcomes, survival, ability

\section{Introduction}

With the development of China's medical technology and the emergence of an aging society, the number of hospitalized patients is higher, the age of patients is older, and the range and number of underlying diseases is greater. This means the general condition of patients has become complex and critical, and in-hospital cardiac arrest (IHCA) is inevitable. It is reported that there are about 200,000 IHCA patients in the United States every year. ${ }^{1}$ At present, extracorporeal cardiopulmonary resuscitation
Department of Nursing, The Second Affiliated Hospital of Nantong University, Nantong, 22600I, People's Republic of China

Tel +86 I38I5219995

Email lihua_wangdr@outlook.com 
(ECPR) remains an economic and effective intervention for patients with IHCA. ${ }^{2}$ The common causes of cardiac arrest include hypovolemia, hypoxia, hypokalemia, hyperkalemia, hypothermia, acute myocardium infarction, tension pneumothorax, tamponade cardiac, toxicosis, and thromboembolism. In China, where citizens' awareness of safeguarding their rights has increased significantly, if the medical staff neglect or do not follow standardized first aid procedures, this will not only affect the quality of the first aid, but also cause doctor-patient disputes. Therefore, it is of great importance to improve the emergency response ability, operation standardization, and organization coordination of medical staff on hospital wards. Quality control inspection is an important means of ensuring the continuous improvement of hospital quality as well as promoting reform and improving the skills of hospital staff. Before 2019, the quality control of first aid carried out by doctors and nurses in the hospital was implemented separately, and standardized first aid skills team training and assessment was focused on the nursing staff ${ }^{3}$. Due to the advance planning arrangement of each department, it has the characteristics of sufficient nurses' manpower arrangement, highly performative, lack of physicians' participation, and extremely incompatible with the clinical emergency status. At this time, the medical department merely issued cardiopulmonary resuscitation (CPR) guidelines to doctors for self-study, but arranged no tracking of their acquired skills. Some studies have found that the use of unannounced on-site simulation exercises is conducive to greater improvement of staff learning and is more effective than off-site training. ${ }^{4}$ Since 2019 , the hospital has implemented group random quality control of on-site medical care. With the continuous involvement of all medical staff and the guidance of a quality control team, by the end of 2020, not only had the first aid ability of the medical and nursing teams in the hospital significantly improved, but also the resuscitation success rate had improved. This paper examines how this was achieved in more detail. Our hypotheses were: (1) Randomized group quality control may improve the emergency operational efficiency of the hospital; (2) Randomized group quality control model may improve the outcome of patients with cardiac arrest in the hospital.

\section{Subjects and Methods} The Establishment of the First Aid Quality Control Team

In December 2018, the first aid quality control team was established and jointly led by the medical department and the nursing department. The team was composed of four doctors (two in the emergency department and two in the intensive care department), eight head nurses, and four emergency specialist nurses. All the team members participated in providing basic life support (BLS) and advanced cardiac life support training in Jiangsu Gulou Hospital training base, validated by the American Heart Association (AHA), and the team member all passed the examination. The leadership of the team was assumed by the most senior doctor, who was responsible for organizing and coordinating the personnel and for arranging the time of each quality control event. The quality control team for the clinical examination had to include the following five people: a doctor, the team leader, who was responsible for overseeing medical records before the examination, and checking the standardization of respiratory management and medical orders in quality control; three head nurses, one who was responsible for checking the quality of venous access management, compression, and defibrillation, one who was responsible for the quality of support for other organ functions, and a third one, who was responsible for checking the quality of the management of the ward and external coordination; and an emergency specialist nurse, who was responsible for preparing and transporting the simulation patient to the clinical sites and for quality control of summary patient records and patient data system input.

\section{Quality Control Methods}

At the beginning of 2019, a total of 47 wards in the hospital participated in the assessment of first aid quality control. The departments involved in this study were as follows: Internal medicine wards (ie respiratory, gastroenterology, rheumatism, endocrinology, cardiology, hematology, oncology, radiotherapy, traditional Chinese medicine, rehabilitation, etc.), Surgery departments (ie orthopedics, cardiac surgery, thoracic surgery, gastrointestinal surgery, breast surgery, burn surgery, brain surgery, etc.), obstetrics and gynecology, pediatrics (except newborns), operating room, gastroscopy room, intensive care unit, and inpatients (except operating room and gastroscopy room). The assessment results of new departments after that date were not included in the study. Each department was assessed every six months, and the assessment results were linked to the performance of the department. Patients were selected according to the characteristics of each department. The symptoms, signs, and progression of the patients were set out according to the ten most 
common reversible causes of cardiac arrest. The quality control team went to the ward to be examined without prior notice and selected an empty bed or public area for a simulation drill. After being alerted, the medical staff on duty had to immediately act as if they were in a real emergency situation. Members of the quality control team checked their performance according to their respective division of labor and the quality assessment form. During the process, only the team leader gave situational prompts, and the emergency specialist nurse was responsible for simulating the patient symptom description, and other quality control members did not speak. After the practical assessment, the quality control team summarized the assessment problems first, and then gave feedback to the doctor and nurse representative. The quality control problems concerning the emergency response skills of the whole hospital were summarized and fed back to medical and nursing staff once a quarter, and any common problems were rectified in a centralized manner.

\section{The Key Contents of Quality Control}

Quality inspection items included BLS exploration, the startup of the emergency rescue team, the organization and coordination of the rescue team leader, airway opening, oxygen therapy, cardiac compression, defibrillation, venous access management, drug use, attention to other organs, nursing records, inspection and result tracking, transportation, and rescue discussion. Because there are only a few night shift medical staff on an ordinary ward, during the night shift the rapid response team (RRT) assist with cardiac compression, endotracheal intubation, and defibrillation, but, during the day shift, when assistance is needed, the anesthesiology department is informed and completes endotracheal intubation by telephone, and the defibrillator and ventilator used are from the same department or borrowed from the instrument and equipment center. The emergency and critical departments carry out all the necessary measures themselves.

\section{Research Indicators}

The research indicators consisted of the following: (1) basic information about the examinees; (2) the quality control results of 47 departments on four occasions; (3) the ranking of problems found in the four major quality control inspections; (4) the proportion of seriously ill and critically ill patients in the hospital; (5) the proportion of CPR patients in inpatients; (6) the percentage of return of spontaneous circulation (ROSC), which refers to the proportion of patients in whom a spontaneous heart rhythm is restored and maintained for more than $20 \mathrm{~min}$ utes after CPR out of the total number of patients undergoing CPR; and (7) the discharge survival rate, which refers to the proportion of patients with ROSC still alive at discharge out of the total number of CPR patients.

\section{Information and Data Collection Methods}

The basic information about the medical staff was filled in directly after the on-site assessment. The examination questions and scores were exported from the nursing management system (Shanghai KingYee Technology Co., Ltd.) to generate Excel tables. The quality control items of the system included the level I and level II indicators of the quality control inspection formulated by the hospital emergency quality control team according to the guidelines of the AHA for cardiopulmonary resuscitation, the consensus of Chinese cardiopulmonary resuscitation experts, and the consensus of Chinese cardiopulmonary resuscitation training experts, ${ }^{5,6}$ and these items were weighted. These items were imported into the information system by engineers, and at a later stage, the contents were fine-tuned according to the guide update at the time. The examiners checked each item one by one according to the assessment form, and the scores of non-standard items were subtracted, and the total score was generated automatically.

For inpatient data collection, the following data and information was obtained from the information section: (1) the total number of inpatients in 2019 and 2020; (2) the number of seriously ill and critically ill patients; (3) the medical record number, name, admission, discharge time and any other basic information of the patient along with the temporary doctor's order including "cardiopulmonary resuscitation" or "cardiac defibrillation." Then, the rescue records of patients who had undergone cardiopulmonary resuscitation and cardiac defibrillation were checked using the hospital information management system (HIS) medical record system (Wuhan Feibo Technology Co., Ltd.) to find out about the resuscitation effect. For patients with a successful resuscitation, their 28-day survival was monitored through their medical history or telephone contact. The following cases were excluded: (1) patients with neonatal asphyxia, (2) patients whose family members were unwilling for them to be resuscitated, (3) patients with pacemakers, and (4) patients with extracorporeal membrane oxygenation. For patients with multiple resuscitations, the resuscitation effect was calculated from the first time. 


\section{Statistical Methods}

The data were statistically analyzed using statistical software SPSS 19.0. Measurement data first underwent a test of normality, then normally distributed measurement data were expressed as mean \pm standard deviation ( $\mathrm{x} \pm \mathrm{SD}$ ) and evaluated using a $t$-test or analysis of variance, while non-normally distributed measurement data were expressed as the median and quartile and evaluated using a rank sum test. Count data were expressed as a percentage (\%) or thousandth (\%o), and compared using a Chi-square test. The value of $\alpha$ was set as 0.05 .

\section{Results}

1. There were no significant differences in the age, gender, member proportion, professional title, shift, and other basic information related to the medical staff participating in the assessment in each department at the four stages $(\mathrm{p}>0.05$, Table 1$)$.

2 . The main problems found during the four quality controls are listed in Table 2. A total of 24 major problems (including those which were duplicated) were recorded, among which the most common were doctor problems $(11,45.83 \%)$, followed by doctor and nurse problems $(9,37.50 \%)$, and then nurse problems $(4,16.67 \%)$. The problems could obviously be rectified after the quality control, and the frequency of the same problems decreased significantly, but the mastery of the frequency and depth of extracorporeal cardiac compression was never up to standard (Table 2).

3. The results of the 47 departments participating in the quality control research were as follows: the scores were $78(73,81)$ in the first half of $2019,82(79,86)$ in the second half of $2019,88(83,90)$ in the first half of 2020 , and $90(88,94)$ in the second half of 2020 . Overall, the results of the four stages showed an increase each time, there was significant difference in the results between each stage $(\mathrm{p}<0.05$, Table 3$)$.

4. There was no statistically significant difference in the proportion of seriously ill in-hospital patients in the hospital between 2020 and 2019 ( $\mathrm{p}>0.05$ ). However, the proportion of critically ill patients ( $p$ $<0.05)$ and the proportion of patients with IHCA ( $p$ $<0.05)$ in 2020 were higher than in 2019 , and the

Table I Comparison of Quality Controls in Four Stages in 47 Departments

\begin{tabular}{|c|c|c|c|c|c|c|c|}
\hline \multicolumn{2}{|l|}{ Item } & \multirow{2}{*}{$\begin{array}{c}\text { First Half } \\
\text { of } 2019 \\
|7|\end{array}$} & \multirow{2}{*}{$\begin{array}{c}\begin{array}{c}\text { Second Half } \\
\text { of } 2019\end{array} \\
177\end{array}$} & \multirow{2}{*}{$\begin{array}{c}\begin{array}{c}\text { First Half } \\
\text { of } 2020\end{array} \\
190\end{array}$} & \multirow{2}{*}{$\begin{array}{c}\begin{array}{c}\text { Second Half } \\
\text { of } 2020\end{array} \\
189\end{array}$} & \multirow[t]{2}{*}{$\mathbf{t} / \chi^{2}$} & \multirow[t]{2}{*}{$P$} \\
\hline Total Number (Persons) & & & & & & & \\
\hline Age (years old) & & $34.18 \pm 6.24$ & $33.94 \pm 5.72$ & $33.29 \pm 5.44$ & $34.32 \pm 5.91$ & 1.153 & 0.327 \\
\hline \multirow[t]{2}{*}{ Gender, person (\%) } & Male & $33(19.30)$ & $30(16.95)$ & $31(16.32)$ & $35(18.52)$ & 0.703 & 0.873 \\
\hline & Female & $138(80.70)$ & $147(83.05)$ & $159(83.68)$ & I54(8I.48) & & \\
\hline \multirow[t]{3}{*}{ Occupation, person (\%) } & Doctor & $50(29.24)$ & $48(27.12)$ & $47(24.74)$ & $47(24.87)$ & 1.969 & 0.922 \\
\hline & Anesthesiologist & $29(16.96)$ & $26(14.69)$ & $32(16.84)$ & $34(17.99)$ & & \\
\hline & Nurse & $92(53.80)$ & $103(58.19)$ & III (58.42) & $108(57.14)$ & & \\
\hline \multirow[t]{4}{*}{ Title, person (\%) } & Primary & II (6.43) & $5(2.82)$ & $13(6.84)$ & $8(4.23)$ & 8.344 & 0.500 \\
\hline & Junior & $78(45.6 \mathrm{I})$ & $87(49.15)$ & $84(44.2 I)$ & $80(42.33)$ & & \\
\hline & Intermediate & $62(36.26)$ & $66(37.29)$ & $78(41.05)$ & $84(44.44)$ & & \\
\hline & Senior & $20(11.70)$ & $19(10.73)$ & $15(7.90)$ & $17(9.00)$ & & \\
\hline \multirow[t]{3}{*}{ Shift, frequency (\%) } & Day shift & $27(57.45)$ & $26(55.32)$ & $28(59.57)$ & $22(46.8 \mathrm{I})$ & 1.867 & 0.931 \\
\hline & Middle shift & $15(31.91)$ & $16(34.04)$ & $15(31.91)$ & $19(40.43)$ & & \\
\hline & Night shift & $5(10.64)$ & $5(10.64)$ & $4(8.5 I)$ & $6(12.77)$ & & \\
\hline $\begin{array}{l}\text { Number of calls to anesthesiology } \\
\text { department, times (\%) }\end{array}$ & & $27(57.45)$ & $29(61.70)$ & $26(55.32)$ & $25(53.19)$ & 0.759 & 0.859 \\
\hline Number of calls to RRT, times (\%) & & $12(25.53)$ & 14(29.79) & $13(27.66)$ & $10(21.28)$ & 0.966 & 0.809 \\
\hline
\end{tabular}

Abbreviation: RRT, rapid response team. 
Table 2 Orders of Main Quality Control Problems in Four Stages

\begin{tabular}{|c|c|}
\hline First Half of 2019 & Second Half of 2019 \\
\hline I.Nonstandard timing of adrenaline use (doctors) & $\begin{array}{l}\text { I.Nonstandard establishment of emergency medical advice: norepinephrine, } \\
\text { dopamine, amiodarone (doctors) }\end{array}$ \\
\hline $\begin{array}{l}\text { 2.Cardiac compression frequency or depth not up to } \\
\text { standard (doctors and nurses) }\end{array}$ & 2.Unclear role of team leader (doctors) \\
\hline $\begin{array}{l}\text { 3.Unclear defibrillation pointer and nonstandard operation } \\
\text { (doctors) }\end{array}$ & 3.Nurse is not skilled in the operation of endotracheal intubation (nurses) \\
\hline 4.Unclear role of team leader (doctors) & $\begin{array}{l}\text { 4.Nonstandard treatment of arrhythmia of doctors: pulse ventricular tachycardia, } \\
\text { non-pulse ventricular tachycardia, ventricular fibrillation, cardiac arrest (doctors) }\end{array}$ \\
\hline $\begin{array}{l}\text { 5.Nonstandard cardiac compression replacement (doctors } \\
\text { and nurses) }\end{array}$ & $\begin{array}{l}\text { 5.Cardiac compression frequency or depth not up to standard (doctors and } \\
\text { nurses) }\end{array}$ \\
\hline $\begin{array}{l}\text { 6.Nurses do not pay attention to other patients in the ward } \\
\text { (nurses) }\end{array}$ & 6.Unclear defibrillation pointer and nonstandard operation (doctors) \\
\hline First Half of 2020 & Second Half of 2020 \\
\hline $\begin{array}{l}\text { I.Simple balloon oxygen storage bag is not fully filled (doctors } \\
\text { and nurses) }\end{array}$ & I.Inadequate preparation before transfer (nurses) \\
\hline $\begin{array}{l}\text { 2. The connection with the first aid team in the hospital is not } \\
\text { close (doctors and nurses) }\end{array}$ & $\begin{array}{l}\text { 2.The nurses' estimation of the remaining amount of oxygen cylinder for transfer } \\
\text { is not in place (nurses) }\end{array}$ \\
\hline 3.Lack of awareness of brain protection (doctors) & 3.Insufficient attention to urine volume (doctors) \\
\hline $\begin{array}{l}\text { 4.Cardiac compression frequency or depth not up to } \\
\text { standard (doctors and nurses) }\end{array}$ & 4.Laboratory test results are not well tracked (doctors) \\
\hline $\begin{array}{l}\text { 5.Nonstandard establishment of emergency medical advice: } \\
\text { norepinephrine, dopamine, amiodarone (doctors) }\end{array}$ & $\begin{array}{l}\text { 5.Cardiac compression frequency or depth not up to standard (doctors and } \\
\text { nurses) }\end{array}$ \\
\hline $\begin{array}{l}\text { 6.Decreased awareness of disinfection and isolation (doctors } \\
\text { and nurses) }\end{array}$ & 6.Decreased awareness of disinfection and isolation (doctors and nurses) \\
\hline
\end{tabular}

Table 3 Comparison of Quality Control Scores in Four Stages

\begin{tabular}{|c|c|c|c|c|c|c|}
\hline & \multicolumn{2}{|c|}{ First Half of 2019} & \multicolumn{2}{|c|}{ Second Half of 2019} & \multicolumn{2}{|c|}{ First Half of 2020} \\
\hline & $Z$ value & $P$ value & $Z$ value & $P$ value & $Z$ value & $P$ value \\
\hline Second half of 2019 & -4.068 & 0.000 & & & & \\
\hline First half of 2020 & -6.869 & 0.000 & -4.992 & 0.000 & & \\
\hline Second half of 2020 & -7.662 & 0.000 & -6.754 & 0.000 & -3.238 & 0.001 \\
\hline
\end{tabular}

ROSC rate was also significantly higher in 2020 than in $2019(p<0.05)$, but there was no significant difference in the discharge survival rate of patients after resuscitation $(\mathrm{p}>0.05$, Table 4$)$.

\section{Discussion}

\section{The Random Quality Control Method, IHCA Emergency State, and Inspection Efficiency}

IHCA can be divided into two types: precursory and unexpected. For precursory IHCA, it is possible to make full preparations in terms of manpower, materials, treatment plan, and family communication in advance, to ensure the quality of rescue, and to improve the psychological preparation of family members, and it can be dealt with in the general emergency room and intensive care unit. In contrast, unexpected IHCA can result in problems such as insufficient manpower, materials not in the best state of preparation, poor coordination between doctors and nurses, and insufficient communication between family members because it happens suddenly, making the first aid busy and chaotic, which not only affects the quality of the treatment, but also increases the possibility of doctor-patient conflicts. This kind of situation can easily occur on an ordinary ward. ${ }^{7}$ One study concluded 
Table 4 Comparison of Resuscitation of IHCA of Inpatients in 2019 and 2020

\begin{tabular}{|l|c|c|c|c|}
\hline & $\mathbf{2 0 1 9}$ & $\mathbf{2 0 2 0}$ & $\chi^{2}$ value & P value \\
\hline Number of inpatients in the whole year (cases) & 72,489 & 64,549 & & \\
Seriously ill patients, cases (\%) & $5693(7.85)$ & $4972(7.70)$ & 1.084 & 0.298 \\
Critically patients, cases (\%) & $6024(8.3 I)$ & $575 I(8.9 I)$ & 15.613 & 0.000 \\
Number of IHCA patients, cases (\%) & $99(1.37)$ & $128(1.98)$ & 7.867 & 0.005 \\
Number of ROSC patients, cases (\%) & $48(48.48)$ & $79(61.72)$ & 3.967 & 0.046 \\
Number of survivors at discharge, cases (\%) & II(II.II) & $21(16.4 I)$ & 1.293 & 0.256 \\
\hline
\end{tabular}

Abbreviations: IHCA, in-hospital cardiac arrest; ROSC, return of spontaneous circulation.

that, after general first aid training, the first aid knowledge and skills of medical staff can be significantly improved, but its effect on clinical practice is not clear because it is divorced from clinical practice. ${ }^{8}$ Random quality control inspection is especially suitable for the emergency state of unexpected IHCA, because through the scene drill, it is not only possible to exercise the emergency handling ability of medical staff, but it also means that the problems in the rescue can be identified and guidelines established for future emergencies. This research project was carried out under the joint leadership of the medical department and the nursing department and was closely related to the assessment of both departments and individuals. Therefore, the medical staff of all the departments attached great importance to it and took quality control inspection seriously and actively rectified any quality control problems. In-hospital CPR is a team emergency exercise with multiple participants, and many key links will be involved at the same time. Quality control is required, and the group quality control method used in this study can not only ensure that each inspector has a focus on quality control, but also ensure that each link has the inspector's attention. In addition, the quality control team leaders are very careful about the setting of the quality control cases in each department, and they consider the characteristics of the special diseases in various departments, combined with common complications and severe disease, to make the case closer to the characteristics of the specialty. Therefore, the group random quality control method is as close as possible to the IHCA emergency state and makes up for the many shortcomings of previous quality control methods by improving the efficiency of the practice of quality control.

\section{Group Random Quality Control and the Improvement of Team Collaboration and First Aid Skills}

In this study, with the passage of time, the ward assessment results improved significantly, suggesting that group random quality control can significantly improve the first aid skills of medical staff. In addition, "tacit cooperation" is particularly important to improving the operational efficiency of a team. Fang et $\mathrm{al}^{9}$ confirmed that through the establishment of a practical first aid team of both doctors and nurses, the arrival time of rescue workers was significantly shortened, and the time points of cardiac compression, and the use of a simple breathing balloon, adrenaline, and defibrillation were significantly advanced. In the process of exercise learning, if the actual ability of the participants and the progress of the patient's condition are not taken into consideration, only simple exercises are carried out based on a script, and it is easy to have an unpredictable experience as in the rescue process of actual cases. ${ }^{10}$ In the period 2015-2019, during the assessment of a planned first aid drill of the nursing team in the hospital, if sudden situations were added to the exercise, ward nurses would often be at a loss as to what to do. Although in 2019 the medical staff on the wards in this study also found it difficult to adapt to an emergency, as they gained more experience, by 2020 the response ability of the medical staff was significantly improved. This is probably due to the participation of doctors in the rescue drill, as well as the improvement of the team leader's awareness and first aid skills. Focusing on the specific problems of the four quality controls stages, it was found that some medical problems could be significantly improved, but the mastery of the frequency and depth of extracorporeal cardiac compression were always not up to standard. One study ${ }^{11}$ revealed that if the quality of the $\mathrm{CPR}$ is poor for even the first four minutes, it will significantly affect the hemodynamics and survival outcomes. Therefore, improving the quality of compression is related to the overall success of the resuscitation. Another foreign study ${ }^{12}$ found that in the actual rescue process, $28.1 \%$ of the trained medical staff failed to reach the standard of compression frequency, and $37.4 \%$ of the trained medical 
staff failed to reach the standard of compression depth. A survey on the quality of cardiac compressions of emergency workers in one hospital in China found that only approximately $50 \%$ of them met the standard. ${ }^{13}$ A recent foreign study ${ }^{14}$ showed that in the process of rescue, only $37 \%$ of cardiac compression frequency and $63.9 \%$ of cardiac compression depth reached the standard. Therefore, there is a long way to go for medical staff on the wards to improve the quality of cardiac compression. ${ }^{15}$

\section{Group Random Quality Control and the ROSC Rate of IHCA}

In 2020, as a result of the COVID-19 pandemic, the total number of patients in the hospital was less than that in 2019 , but the proportion of critically ill patients was significantly higher $(8.91 \%$ vs $8.31 \%, \mathrm{p}<0.05)$. The incidence of IHCA was also significantly higher in 2020 than in 2019 ( $p<0.05)$ and slightly higher than that reported in the UK (1.6\%o), ${ }^{16}$ but lower than the level of $3.99 \%$ reported by Liu et al in China. ${ }^{17}$ The ROSC rate in IHCA $(61.72 \%)$ was significantly higher than that in 2019 $(48.48 \%)$, and higher than that $(22.0 \%)$ reported by Liu et al in China. ${ }^{17}$ The reason may be that the hospital not only has an RRT, but also actively takes continuous quality improvement measures to improve the first aid ability of medical staff on the wards. Compared with foreign countries, the ROSC rate of IHCA in the hospital was slightly higher than the $53.8 \%$ reported by Andersen in Denmark ${ }^{18}$ and similar to the $62.5 \%$ reported by Kaplow in the United States $^{14}$ and the $64 \%$ reported by Kaki et al in Saudi Arabia. ${ }^{19}$ In addition, in this study, there was no significant difference in the discharge survival rate of CPR patients between 2019 and 2020 (11.11\% vs 16.41\%), the reason probably being that the survival rate is also related to the patient's condition, treatment effect, and other factors. However, this result was slightly lower than the discharge survival rate of $15-23.5 \%$ reported in the United States, ${ }^{14,20,21}$ the $23.76 \%$ reported in Thailand, ${ }^{22}$ and the $30 \%$ reported by Kaki et al in Saudi Arabia. ${ }^{19}$ The reason may be that in view of the medical conditions and treatment levels of hospitals in various countries, there will be significant differences in the survival rate of in-hospital resuscitation between hospitals. ${ }^{23}$

With regard to this study, the objectives, schemes, and assessment tools of hospital first aid quality assessment before this study were completely different from those after 2019, but the historical control design could not be assessed any longer, so it was only possible to compare the results of the immature implementation (2019) and mature implementation (2020) of the group random quality control scheme. Moreover, because of the short study period, the number of cases was relatively small, and so the results of the comparison may not be accurate. A multi-center large sample randomized controlled study should be carried out. Additionally, the indicators of neurological status of these patients were not analyzed due to incomplete clinical data. Future studies including these indicators are needed to validate the current findings.

\section{Summary}

Group random quality control is a continuous quality improvement method involving both doctors and nurses. The implementation plan conforms to the emergency state of IHCA, and it can also improve the first aid skills and organizational coordination of doctors and nurses on the ward through continuous discovery and rectification of problems as they occur, with a view to ultimately improving the success rate of resuscitation. Therefore, group random quality control is worthy of clinical reference and more widespread use.

\section{Ethical Statement}

This study was conducted in accordance with the declaration of Helsinki. This study was conducted with approval from the Ethics Committee of The Second Affiliated Hospital of Nantong University. Written informed consent was obtained from all participants.

\section{Funding}

Jiangsu Hospital Association Hospital Management Innovation Research Project, No. JSYGY-3-2020-70.

\section{Disclosure}

The authors report no conflicts of interest in this work.

\section{References}

1. Merchant RM, Yang L, Becker LB, et al; American Heart Association Get With The Guidelines-Resuscitation Investigators. Incidence of treated cardiac arrest in hospitalized patients in the United States. Crit Care Med. 2011;39(11):2401-2406. PMID: 21705896; PMCID: PMC3196742. doi:10.1097/CCM.0b013e3182257459

2. Gravesteijn BY, Schluep M, Voormolen DC, et al. Cost-effectiveness of extracorporeal cardiopulmonary resuscitation after in-hospital cardiac arrest: a Markov decision model. Resuscitation. 2019;143:150-157. PMID: 31473264. doi:10.1016/j.resuscitation. 2019.08.024 
3. Zhang LR, Song GQ, Xie SQ, et al. Implementing team resuscitation training to improve the timeliness of CPR. J Nurs. 2012;19(6):24-27.

4. Sørensen JL, Østergaard D, LeBlanc V, et al. Design of simulation-based medical education and advantages and disadvantages of in situ simulation versus off-site simulation. BMC Med Educ. 2017;17(1):20. PMID: 28109296; PMCID: PMC5251301. doi:10.1186/s12909-016-0838-3

5. Neumar RW, Shuster M, Callaway $\mathrm{CW}$, et al. Part 1: executive summary: 2015 American heart association guidelines update for cardiopulmonary resuscitation and emergency cardiovascular care. Circulation. 2015;132(18Suppl 2):S315-S367. PMID: 26472989. doi:10.1161/CIR.0000000000000252

6. Wang L, Meng Q, Yu T; Cardiopulmonary Resuscitation Specialized Committee of Chinese Research Hospital Association; the Science Popularization Branch of the Chinese Medical Association. [2018 national consensus on cardiopulmonary resuscitation training in China]. Zhonghua Wei Zhong Bing Ji Jiu Yi Xue. 2018;30 (5):385-400. Chinese. PMID: 29764540. doi:10.3760/cma.j. issn.2095-4352.2018.05.001

7. Yu L, Jiang JX, Wang CY, Chen Y, Fang J, Hong D. Establishment and operating effectiveness research of the rapid response team. J Nurs Adm. 2017;17(11):847-849.

8. Huang J, Tang Y, Tang J, et al. Educational efficacy of high-fidelity simulation in neonatal resuscitation training: a systematic review and meta-analysis. BMC Med Educ. 2019;19(1):323. PMID: 31464614; PMCID: PMC6716944. doi:10.1186/s12909-019-1763-z

9. Fang LY, Chen T, Cao HL, Tong YF, Wu MF, Chen LJ. Construction and effectiveness evaluation of emergency management team model in endoscopy center under public platform. Chin J Emerg Med. 2020;29(10):1367-1369.

10. Chen S, Zhou J, Zhu CY, Zou SQ. Evaluation of problem-based learning combined with scene simulation in cardiopulmonary resuscitation teaching of standardized training of general practitioner. Chin J Med Educ Res. 2020;19(05):598-601.

11. Li H, Zhang L, Yang Z, et al. Even four minutes of poor quality of CPR compromises outcome in a porcine model of prolonged cardiac arrest. Biomed Res Int. 2013;2013:171862. PMID: 24364028; PMCID: PMC3865628. doi:10.1155/2013/171862

12. Abella BS, Alvarado JP, Myklebust H, et al. Quality of cardiopulmonary resuscitation during in-hospital cardiac arrest. JAMA. 2005;293(3):305-310. PMID: 15657323. doi:10.1001/ jama.293.3.305

13. Cui QH, Wang Y, Fu YY, et al. Study of performance of cardiopulmonary resuscitation in emergency department of Peking union medical college hospital. J Clin Emerg. 2016;17(7):535-537.
14. Kaplow R, Cosper P, Snider R, et al. Impact of CPR quality and adherence to advanced cardiac life support guidelines on patient outcomes in in-hospital cardiac arrest. AACN Adv Crit Care. 2020;31(4):401-409. PMID: 33313710. doi:10.4037/aacnacc2020297

15. Yu T. Implementation of high quality $\mathrm{CPR}$ — from guide to practice. Chin J Emerg Med. 2015;24(1):17-21.

16. Nolan JP, Soar J, Smith GB, et al; National Cardiac Arrest Audit. Incidence and outcome of in-hospital cardiac arrest in the United Kingdom national cardiac arrest audit. Resuscitation. 2014;85 (8):987-992. PMID: 24746785. doi:10.1016/j. resuscitation.2014.04.002

17. Liu YQ, Zhang YX, Hou Q, Xiong XZ, Jing YX, Shi XY. The effect of rapid response system on improving the success rate of patients with cardiac respiratory arrest in hospital. J Hunan Normal Univ. 2019;16(02):180-183.

18. Andersen LW, Holmberg MJ, Løfgren B, Kirkegaard H, Granfeldt A. Adult in-hospital cardiac arrest in Denmark. Resuscitation. 2019;140:31-36. PMID: 31075290. doi:10.1016/j. resuscitation.2019.04.046

19. Kaki AM, Alghalayini KW, Alama MN, et al. An audit of in-hospital cardiopulmonary resuscitation in a teaching hospital in Saudi Arabia: a retrospective study. Saudi J Anaesth. 2017;11(4):415-420. PMID: 29033721; PMCID: PMC5637417. doi:10.4103/sja.SJA_255_17

20. Goldberger ZD, Chan PS, Berg RA, et al; American Heart Association Get With The Guidelines-Resuscitation (formerly National Registry of Cardiopulmonary Resuscitation) Investigators. Duration of resuscitation efforts and survival after in-hospital cardiac arrest: an observational study. Lancet. 2012;380(9852):1473-1481. PMID: 22958912; PMCID: PMC3535188. doi:10.1016/S01406736(12)60862-9

21. Feingold P, Mina MJ, Burke RM, et al. Long-term survival following in-hospital cardiac arrest: a matched cohort study. Resuscitation. 2016;99:72-78. PMID: 26703463; PMCID: PMC4835345. doi:10.1016/j.resuscitation.2015.12.001

22. Limpawattana P, Aungsakul W, Suraditnan C, et al. Long-term outcomes and predictors of survival after cardiopulmonary resuscitation for in-hospital cardiac arrest in a tertiary care hospital in Thailand. Ther Clin Risk Manag. 2018;14:583-589. PMID: 29593417; PMCID: PMC5865579. doi:10.2147/TCRM.S157483

23. Girotra S, Cram P, Spertus JA, et al; American Heart Association's Get With the Guidelines ${ }^{\circledR}$-Resuscitation Investigators. Hospital variation in survival trends for in-hospital cardiac arrest. $J$ Am Heart Assoc. 2014;3(3):e000871. PMID: 24922627; PMCID: PMC4309112. doi:10.1161/JAHA.114.000871
Risk Management and Healthcare Policy

\section{Publish your work in this journal}

Risk Management and Healthcare Policy is an international, peerreviewed, open access journal focusing on all aspects of public health, policy, and preventative measures to promote good health and improve morbidity and mortality in the population. The journal welcomes submitted papers covering original research, basic science, clinical \& epidemiological studies, reviews and evaluations, guidelines, expert opinion and commentary, case reports and extended reports. The manuscript management system is completely online and includes a very quick and fair peer-review system, which is all easy to use. Visit http://www.dovepress.com/testimonials.php to read real quotes from published authors. 